\title{
Epilasyonda IPL'in (Yoğun Atımlı Ișı) Etkinlik ve Güvenilirliğinin Retrospektif Olarak Değerlendirilmesi
}

\author{
The Retrospective Evaluation of the Efficacy and Safety of IPL \\ (Intense Pulse Light) in Hair Removal
}

\section{Illgen Ertam, Ezgi Erçal, İdil Ünal, Sibel Alper}

Ege Üniversitesi Tıp Fakültesi, Deri ve Zührevi Hastalıklar Anabilim Dalı, İmir, Türkiye

\section{Özet}

Amaç: Istenmeyen kıllara yönelik tedaviler her geçen gün artmakta ve bașarı sonuçları değișkenlik göstermektedir. Bu araștırmada amaç, epilasyonda IPL yönteminin etkinlik ve yan etkilerinin değerlendirilmesidir.

Gereç ve Yöntem: Kıllanma șikayetiyle bașvuran ve IPL yapılan 90 hastanın sonuçları retrospektif olarak incelendi. Uygulama yüz, boyun, aksiller, bikini, sternum, periareolar alan, kol ve bacaklara yapıldı. Epilasyon ișlemi için Intense Pulse Light (L900 A\&M, France) aleti kullanıldı. Sonuçlar klinik iyileșme (\%0-25, 25-50, 50-75, 75 ve üzeri) ve hasta memnuniyetine (çok memnun, orta memnun, az memnun, memnun değil) göre değerlendirildi. Verilerin istatistiksel analizinde SPSS 15.0 programında Ki-kare testi kullanıldı.

Bulgular: Doksan hastanın 88 (\%97,8)'i kadın, $2(\% 2,2)$ 'si erkek idi. Yașları 15-55 $(33,62 \pm 11,11)$ arasında değișmekteydi. Hastaların $\% 13,3$ 'ünde polikistik over sendromu saptandı. Uygulanan seans sayısı ortalama 6,5 (2-11) idi. Tüm lokalizasyonlarda hastaların $\% 53,2$ 'sinde $\% 50-75$ arası iyileșme elde edildi ve \%53.2'si tedaviden orta derecede memnun olduklarını ifade ettiler.

Sonuç: Hastalarımızda, epilasyon için uygulanan IPL yöntemi'nin güvenli ve orta derecede etkili olduğu bulunmuștur.

(Türkderm 2012; 46: 94-7)

Anahtar Kelimeler: Epilasyon, tedavi, yoğun atımlı ıșı

\section{Summary}

Background and Design: There are numerous therapeutic methods for hair removal with various success rates. The aim of this study was to evaluate the efficacy of Intense Pulse Light (IPL) method for hair removal.

Materials and Methods: Ninety patients, who applied for their unwanted hair, were included in the study. IPL was applied to the face, neck, axillary areas, bikini line, sternal area, periareolar areas, and upper and lower extremities. An IPL device (L900 A\&M, France) was used for hair removal. The results were evaluated according to the clinical improvement (0-25\%, 25-50\%, 50-75\%,75\% and more) and patients' satisfaction (very satisfied, satisfied, less satisfied, not satisfied). All results were analyzed using Chi-square test and statistical analysis was performed by SPSS 15.0 for Windows.

Results: There were eighty-eight female (97.8\%) and two male (2.2\%) patients. The mean age of the patients was $33.62 \pm 11.11$ (1555) years. $13.3 \%$ of patients had polycystic ovary syndrome. The mean number of treatments was 6.5 (min-max $=2-11) .53 .2 \%$ of patients had $50-75 \%$ clinical response and $53.2 \%$ of patients were satisfied. There were no side effects except mild erythema. Conclusion: We observed that IPL for hair removal was safe and moderately effective in our patients. (Turkderm 2012; 46: 94-7) Key Words: Hair removal, treatment, Intense pulse light

\section{Giriş}

Lazer (Light Amplification by Stimulated Emission of Radiation) ve Intense pulse light (IPL) sistemleri son yıllarda gerek epilasyon, gerekse deri yenileme, pigmentasyon ve vasküler hastalıkların tedavisinde yaygın olarak kullanılmaktadır. IPL, 500-1200 nm dalga boyunda yüksek yoğunlukta ışık üretir ve etki mekanizması seçici fototermoliz esasına dayanır. Bu yöntemde uygulama yapılan klinik tabloya göre hedef kromofor değişmektedir. vasküler lezyonda hedef kromofor hemoglobin iken, epilasyonda ise foliküler melanindir ${ }^{1-3}$.

Mevcut olan tüm lazer ve IPL yöntemlerinde tam bir epilasyon (\%100) yanıtı oluşması günümüzde hemen hemen mümkün değildir. Uzun yıllardan beri epilasyonda en uygun lazer

Yazıșma Adresi/Address for Correspondence: Dr. Ilgen Ertam, Ege Üniversitesi Tip Fakültesi, Deri ve Zührevi Hastallklar Anabilim Dall, lzmir, Türkiye Tel.: +90 2323903831 E-posta: ilgen.ertam@ege.edu.tr Geliş Tarihi/Received: 08.07.2010 Kabul Tarihi/Accepted: 06.09.2011

Türkderm-Deri Hastalıkları ve Frengi Arșivi Dergisi, Galenos Yayınevi tarafindan basılmıștır. Turkderm-Archives of the Turkish Dermatology and Venerology, published by Galenos Publishing. 
yönteminin ne olduğu araştırılmaktadır. IPL ile epilasyon sonrası başarı oranları değişkenlik göstermektedir. Genel kanı, maksimum etki için aletlerin kombine kullanı Imaları şeklindedir1,2,4-6.

Ulaşılabilen literatürde ülkemizde IPL ile ilgili çalışma bulunmamakta olup çalışmamız bu açıdan ilk olma özelliğindedir. Bu çalışmanın amacı; IPL ile yapılan epilasyonun kısa dönem etkinliğini ve yan etkilerini değerlendirmektir.

\section{Gereç ve Yöntem}

Bu araştırma; Aralık 2005-Mart 2008 tarihleri arasında Ege Üniversitesi Tıp Fakültesi, Deri ve Zührevi Hastalıklar Anabilim Dalı Kozmetoloji Birimi'nde yapıldı. Araştırmada, kliniğimize kıllanma şikayetiyle başvuran 90 hastanın dosyası retrospektif olarak incelendi. Dışlama kriterleri, gri, sarı, beyaz renkli kılların varlığı, bronz deri, fotosensitivite, gebelik ve laktasyon, immunsupresif tedavi altında olanlar olarak belirlenmişti.

Lokalizasyon yüz (çene, bıyık bölgesi, malar ve mandibuler bölge, zigomatik bölge) boyun, aksiller bölge, bikini, sternum, periareoler alan, kol ve bacaklara IPL uygulamaları değerlendirildi.

Çalışmaya dahil edilen .tüm hastaların hirsutism dışında dermatolojik bakıları normaldi. Hastaların FSH, (folikül stimülan hormon), LH (Luteinizan hormon), PRL (prolaktin), 17- alfa hidroksiprogesteron, DHEAS (Dihidroepiandrosteronsülfat), serbest testosteron ve total testosteron testleri kayıtları incelendi. Polikistik over sendromu tanısı olan hastalar Endokrinoloji ve Jinekoloji tarafından tanısı konmuş ve tedavileri sürmekteydi.

Epilasyon işlemi için Intense Pulse Light (L900 A\&M, France) aleti kullanıldı. L900 sistemin dalga boyu 620-1000nm , fluence değerleri 11$14 \mathrm{mj} / \mathrm{cm}^{2}$ spot büyüklüğü $5 \mathrm{~cm}^{2}$ idi. Cihaz kıl tipi ve deri tipinin belirlenmesinin ardından dozu otomatik olarak belirlemekteydi. Hastalara IPL tedavisi ilk seanstan bir ay sonra uygulandı. Daha sonra 1-3 ay arasında değişen sürelerde IPL uygulaması yapıldı. Tedaviden önce kıllar en fazla $1 \mathrm{~mm}$ uzunlukta olmak üzere traş edildi ve işlemden hemen önce soğutucu jel uygulaması yapıldı.

Elde edilen yanıt kıllarda \%0-25, \%25-50, \%50-75 ve \%75 üzeri azalma şeklinde değerlendirildi (4 nokta skalası).

Tedavi öncesi ve sonrasında uygulanan bölgelerin fotoğrafları çekildi. Tedaviye başlamadan önce hastalar tedavi konusunda bilgilendirildi ve yazılı onamları alındı.

İstatistiksel değerlendirmede polikistik over sendromu olan ve olmayan hastaların sonuçları karşılaştırıldı. Verilerin istatistiksel analizinde SPSS 15,0 programında Ki-kare testi kullanıldı. P değeri <0,05 anlamlı olarak kabul edildi.

\section{Bulgular}

Dosyaları retrospektif olarak incelenen 90 hastanın 88'i $(\% 97,8)$ kadın, 2'si erkekti $(\% 2,2)$. Yaşları 15-55 $(33,62 \pm 11,11)$ arasında değişmekteydi. IPL uygulaması 90 hastanın 141 bölgesine yapılmıştı. Kayıtlarda kadın hastaların 12'sinde $(\% 13,3)$ polikistik over sendromu tespit edilmişti ve bu hastalara tıbbi tedavi ile birlikte IPL tedavisi devam edilmişti.

Hastaların 33'ü $(\% 12,1)$ Fitzpatrick deri tipi 2, 57'si $(\% 20,9)$ deri tipi 3, 1 tanesi $(\% 0,4)$ deri tipi 4 idi.

Tüm lokalizasyonlar bir arada değerlendirildiğinde hastaların \%53,2'sinde ( $n=39) \% 50-75$ arası iyileşme elde edildi ve \%53,2'si ( $n=38$ ) tedaviden orta derecede memnun olduklarını ifade etmişlerdi (Tablo 1).
Verilerin istatistiksel analizinde, lokalizasyona göre klinik iyileşme oranları açısından anlamlı bir fark saptanmadı $(p=0,233)$. Hasta memnuniyeti en fazla aksiller bölge uygulamalarında görülürken, en az kol ve yüz bölgesinde idi.

En uzun tedavi seansı gerektiren bölge yüz (çene, bıyık, malar ve mandibuler alan) bölgesiydi (11 seans) (Tablo 2).

En iyi klinik iyileşme, sırasıyla aksiller (Resim 1a-1b), bikini, sternal ve areoler bölge, bacak, linea nigra, malar mandibuler, bıyık, çene (Resim 2a-2b) alanlarında elde edilmişti.

Lokalizasyona göre memnuniyet oranları şu şekildedir: Çene $(n=52)$ bölgesinde hastaların \%48, 1'i ( $n=25)$, bıyık bölgesinde ( $n=30)$ hastaların $\% 50$ 'si ve aksillada $(n=15)$ ise hastaların \%46,7'si orta derecede memnun olduklarını ifade etmişlerdi.

Tablo 1. IPL uygulanan hastaların cinsiyet, ortalama klinik iyileşme ve memnuniyet oranları

\begin{tabular}{|l|c|}
\hline Cins & $\mathbf{n}(\%)$ \\
\hline Kadın & $88(97,8)$ \\
\hline Erkek & $2(2,2)$ \\
\hline Toplam & $90(100)$ \\
\hline Klinik iyileşme & $19(13,5)$ \\
\hline$\% 75$ üzeri & $75(53,2)$ \\
\hline$\% 50-75$ & $40(28,4)$ \\
\hline$\% 25-50$ & $7(5)$ \\
\hline$\% 25$ altı & $141(100)$ \\
\hline Toplam & \\
\hline Memnuniyet & $22(15,6)$ \\
\hline Çok memnun & $75(53,2)$ \\
\hline Orta düzeyde memnun & $36(25,5)$ \\
\hline Az memnun & $8(5,7)$ \\
\hline Memnun değil & $141(100)$ \\
\hline Toplam & \\
\hline
\end{tabular}

Tablo 2. Uygulanan alan ve ortalama seans sayıları

\begin{tabular}{|l|c|cc|}
\hline Uygulanan alan & $\mathbf{n}$ & \multicolumn{2}{|c|}{$\begin{array}{c}\text { Seans sayısı } \\
\text { (mean, min-max) }\end{array}$} \\
\hline Çene & 52 & 5, & $1-11$ \\
\hline Bıyık & 30 & 5, & $1-11$ \\
\hline Malar+mandibuler alan & 13 & 5, & $1-11$ \\
\hline Aksilla & 15 & 4, & $1-8$ \\
\hline Bikini & 5 & 3, & $1-4$ \\
\hline Zigomatik & 2 & 6, & $5-7$ \\
\hline Linea nigra & 6 & 4, & $3-6$ \\
\hline Kol & 4 & 2,5, & $2-5$ \\
\hline Boyun & 5 & 5, & $3-8$ \\
\hline Sternal bölge & 2 & 6,5, & $3-10$ \\
\hline Periareolar alan & 6 & 4, & $3-10$ \\
\hline Bacak & 1 & 3, & $3-3$ \\
\hline Toplam & 141 & & \\
\hline
\end{tabular}




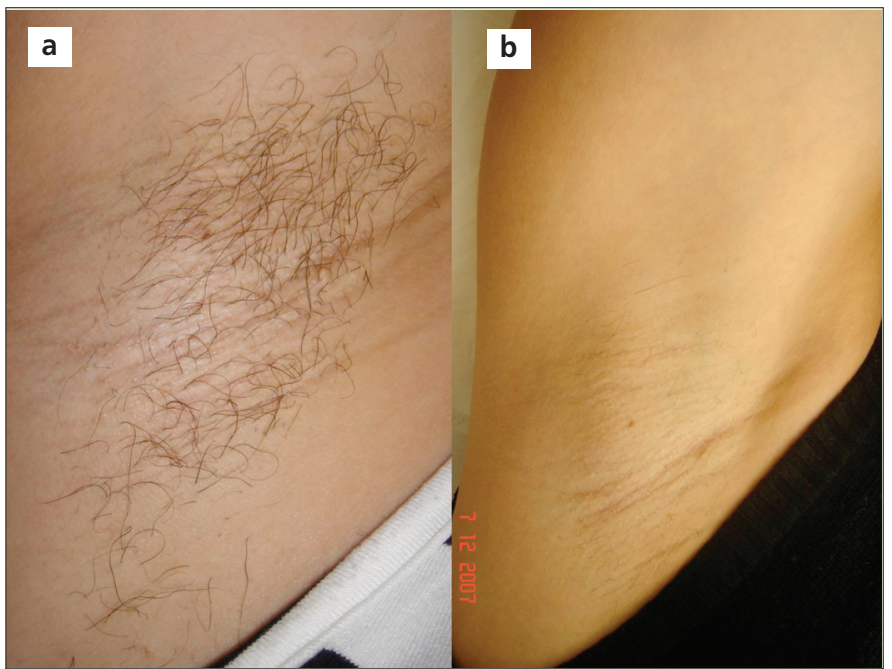

Resim 1. Aksiller bölge tedavi öncesi (a) ve tedavi sonrası (b) görünümü.

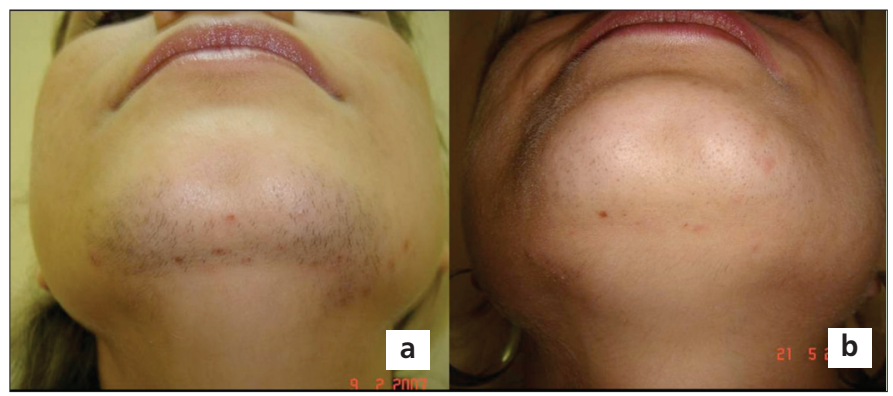

Resim 2. Çene bölgesi tedavi öncesi (a) ve tedavi sonrası (b) görünümü.

Lokalizasyona göre klinik iyileşme oranları açısından, en iyi yanıt veren bölge olan aksillaya uygulama yapılan hastaların \%46,7'si \%75 ve üzeri, $\% 46,7$ 'si \%50-75 iyileme oranlarına sahipti.

Polikistik over sendromu olan ve olmayan grup tedavi yanıtları açısından karşılaştırıldığında anlamlı fark gözlenmedi $(p=0,465)$.

Tedavi sonrası kalıcı ve şiddetli yan etki gözlenmemişti. Hastalarda tedaviden hemen sonra eritem, hafif yanma hissi, perifolliküler eritem gözlenmişti. Bu bulgular soğuk uygulama ile gerilemişti. Skar ya da postinflamatuvar hiper ya da hipopigmentasyon gözlenmemişti.

\section{Tartışma}

Intense Pulse Light (IPL) yönteminin epilasyondaki etkinliğini araştırdığımız bu retrospektif çalışmada hastaların \%53,2'inde \%50-75 arası iyileşme elde edilmişti. Hastaların \%53,2'si ise, tedaviden orta derecede memnun olduklarını ifade etmişlerdi. Lokalizasyona göre klinik iyileşme oranları açısından, aksiller bölge hem yanıt hem de memnuniyet oranları açısından en iyi yanıt alınan bölge idi.

Lazer ya da IPL sistemlerinde epilasyonun başarısı kılın yapısına ve kılın bulunduğu evreye göre değişmektedir. Aksiller bölge, inguinal ve alt ekstremite en iyi sonuç alınan bölgelerdir. IPL ile fototermoliz uygulandığında en iyi sonucu anajen fazdaki kıllar vermektedir. Çünkü anajen fazda melanin oranı daha fazladır. Kılın termolizisi ile, beslenmesi ve büyümesini sağlayan dış kılıfı ısınarak indirek termal hasar oluşur. Kıl ne kadar koyu renkli ve kalınsa o kadar çok enerji tutar ve hasar da o oranda yüksek olur1-3,7,8.
Epilasyonda IPL ilk kez 1997 yılında iki olguda 6 ay süre ile kullanılmış ve yan etki gözlenmeksizin sakal bölgesinde iyi yanıt elde edilmiştir². Daha sonra ise IPL yaygın kullanılmaya başlanmıştır.

IPL tedavisinde seansların sıklığı ve maksimum kaç seans yapılması gerektiği ile ilgili bilgiler de farklılık göstermektedir. Sadick ve ark. ortalama 3 IPL seansından sonra \%76 oranında azalma olduğunu bildirmişlerdir ${ }^{9}$. IPL'in, bir ay ara ile 6-19 ay süre uygulanması önerilse de $^{9}$, bazı yayınlarda en fazla yedi seans ${ }^{7}$, bazı yayınlarda ise, üç seanstan fazla uygulanmasının etkinliği arttırmadığı bildirilmektedir ${ }^{10}$. Biz de kayıtların değerlendirilmesinde, hastalarımızda beş seanstan sonra klinik yanıtta azalma olduğunu gözlemledik.

Fodor ve ark. 108 hastaya 1-13 seans arasında IPL (Epilight) epilasyon uygulamışlar ve hastaların \%60'ında iyi-mükemmel memnuniyet sonuçları elde etmişlerdir ${ }^{1}$. Schroeter ve ark. deri tipi 1-5 olan 70 hastada 2-23 seans arası IPL uygulaması sonrası \%87 başarı ve en uzun tedavi süresinin açık renkli kıllarda olduğunu bildirmişlerdir ${ }^{10}$.

Çok merkezli bir çalışmada, 52 kadın hastanın aksiller bölgesine 1-5 seans IPL uygulanmış ve etkili, güvenli, iyi tolere edilen, hasta memnuniyetinin yüksek olduğu bir yöntem olduğu bildirilmiştir ${ }^{11}$. Bir çalışmada ise aksiller bölgede \%83,4'e ulaşan yanıt oranları elde edilmiştir12. Bizim sonuçlarımızda da da en iyi sonuç ve memnuniyet oranı aksiller bölgede elde edilmişti.

Farklı bir IPL sistemi olan VPL (Variable pulse light)'nin özelliği mikroatımlar şeklinde uygulama yapılmasıdır. VPL'nin yüz dışı alanlarda özellikle Fitzpatrick deri tipi III ve IV'te siyah kıllarda etkili olduğu bildirilmiştir ${ }^{13}$.

Son yıllarda IPL ve radyofrekans kombinasyonları ile başarılı sonuçlar alınmaktadır. Bu teknoloji ışık ve elektrik enerjilerini anında birleştirmektedir. Bu kombine sistemlerin açık renkli kıllarda da etkili olduğu ve ortalama sekiz seansta kıllarda \%57,4 azalma elde edildiği bildirilmektedir ${ }^{3}$. Bu yöntemin koyu tenli kişilerde epilasyonda güvenli olduğu bildirilmiştir14

IPL yöntemi diğer lazer yöntemleri ile de etkinlik açısından karşılaştırılmıştır ve sonuçlar değişkenlik göstermektedir. Yapılan bir çalışmada, hirsutismusu olan hastalarda, yüz bölgesi uygulamasında altı seans sonunda Alexandrite lazerin IPL yöntemine göre anlamlı olarak daha etkili olduğu saptanmıştır. Genç hasta ve daha önce mekanik yöntem uygulanmamış olmasının başarı şansını arttırdığı, ancak hormon düzeyleri ile başarı oranı arasında ilişki bulunmadığı bildirilmiştir16. Ancak, bir başka araştırmada ise, Alexandrite ve IPL arasında epilasyon sonuçları açısından bir fark bulunmamıştır. Yan etki olarak Alexandrite lazerde \%3,1 oranında özellikle yüz ve boyunda tedavi edilen alan çevresinde paradoksal kıllanma gelişimi bildirilmiştir ${ }^{1}$. Bjerring ve ark. 31 olguda ruby lazer ve IPL'i karşılaştırmışlar, üç uygulamadan sonra ruby lazerde \%54,8, IPL'de \%93,5 azalma saptamışlardır7.

Hormonal bozukluğu olan kişilerde (polikistik over sendromu, hiperandrojenizm gibi) IPL ve diod lazer tedavisinin etkinliği konusunda yapılan bir çalışmada hormonal düzeyi normal olan kişilerle aynı oranda yanıt alındığı ancak 6 ayda etkinliğin azaldığı bildirilmiştir17. Biz de araştırmamızda hormonal düzeyi normal ve polikistik over sendromu olan hastalar arasında IPL'e yanıt açısından istatistiksel olarak anlamlı bir fark saptamadık.

Fitzpatrick deri tipi IV-V olanlarda IPL tedavisi ile komplikasyon gelişme riski yüksektir. IPL yöntemine bağlı komplikasyonlar, uzun süren eritem, bül gelişimi, geçici hiperpigmentasyon, lökotrişi, kalıcı hipopigmentasyon, paradoksal kıllanma gelişimi şeklinde sıralanabilir18. Bir çalışmada IPL uygulaması ile en sık görülen yan etki \%16,3 oranında eritem olarak bildirilmiştir. Diğer yan etkiler; krut ve vezikül gelişimi, kalıcı 
hipopigmentasyon, geçici hiperpigmentasyon ${ }^{1}$ şeklinde sıralanmıştır. Hastalarımızın dosyalarının incelenmesinde, geçici eritem, hafif yanma hissi ve perifoliküler eritem dışında yan etki saptanmadı.

Yüz bölgesi epilasyon yöntemlerine en zor yanıt veren bölgedir. Bu nedenle kalıcı epilasyon zordur. Çalışmamızda da yüz bölgesi klinik iyileşme ve memnuniyet oranları açısından en düşük yanıt alınan bölge olmuştur. Sonuç olarak, IPL'in epilasyonda klinik iyileşme ve hasta memnuniyeti açısından orta düzeyde etkili ve yan etki açısından ise güvenli olduğu saptanmıştır. Bu nedenle, yöntemin başka alternatif metodlarla (farklı lazer türleri) kombine edilmesinin başarı oranını arttıracağı sonucuna varılmıştır.

\section{Kaynaklar}

1. Fodor $L$, Menachem $M$, Ramon $Y$ et al: Hair removal using intense pulse light (Epilight):patient satisfaction, our experience and literature review. Ann Plast Surg 2005;54:8-14.

2. Raulin C, Werner $S$, Hartschuh W et al: Effective treatment of hypertrichosis with pulsed light: a report of two cases. Ann Plast Surg 1997;39:169-73.

3. Schroeter CA, Sharma S, Mbonu NC, Reineke T, Neumann HA: Blond hair removal using ELOS systems. J Cosmet Laser Ther 2006;8:82-6.

4. Tierney EP, Goldberg DJ: Laser hair removal pearls. J Cosmet Laser Ther 2008;10:17-23.

5. Haedersdal M, Wulf HC: Evidence-based review of hair removal using lasers and light sources. J Eur Acad Dermatol 2006;20:9-20.

6. Bjerring $P$, Cramers $M$, Egekvist $H$ : Hair reduction using a new intense pulsed light irradiator and a normal mode ruby laser. J Cutan Laser Ther 2000;2:63-71.

7. Nouri K, Vejjabhinanta V, Patel SS, Singh A: Photoepilation:a growing trend in laser-assisted cosmetic dermatology. J Cosmet Dermatol 2008;7:61-7.
8. Lipper GM, Anderson RR: Lasers in Dermatology. Fitzpatrick's Dermatology of General Medicine'de. Ed. Freedberg IM, Eisen AZ, Wolff KK et al. Newyork, McGraw Hill, 2003;2493-515.

9. Sadick NS, Weiss RA, Shea CR: Long-term photoepilation using a broadspectrum intense pulsed light source. Arch Dermatol 2000;136:1336-40.

10. Schroeter CA, Groenewegen JS, Reineke T, Neumann HA: Hair reduction using intense pulse light source. Dermatol Surg 2004;30:168-73.

11. Ancona D, Stuve R, Trelles MA: A multicentre trial of the epilation efficacy of a new, large spot size, constant spectrum emission IPL device. Journal of Cosmetic and Laser Therapy. 2007;9:139-47.

12. Hee Lee J, Huh $\mathrm{CH}$, Yoon HJ, Cho KH, Chung JH: Photo-epilation results of axillary hair in dark-skinned patients by intense pulsed light: comparison between different wavelengths and pulse width. Dermatol Surg 2006;32:234-40.

13. Holzer G, Nahavandi H, Neumann R, Knobler R. Photoepilation with variable pulse light in non-facial body areas: evaluation of efficacy and safety. JEADV 2010;24;518-23.

14. Yaghmai D, Garden JM, Bakus AD, Spenceri EA: Hair removal using a combination radio-frequency and intense pulsed light source. I Cosmet Laser Ther 2004;6:201-7.

15. McGill DJ, Hutchison C, McKenzie E, McSherry E, Mackar IR: A randomised, split-face comparison of facial hair removal with the Alexandrite laser and Intense Pulsed Light system. Lasers in Surgery and Medicine 2007;39:767-72.

16. Marayiannis KB, Vlachos SP, Savva MP, Kontoes PP: Efficacy of long- and short pulse alexandrite lasers compared with an intense pulsed light source for epilation: a study on 532 sites in 389 patients.J Cosmet Laser Ther. 2003;5:140-5.

17. Haak CS, Nymann P, Pedersen AT, et al. Hair removal in hirsute women with normal testosterone levels: a randomizedcontrolled trial of long-pulsed diode laser vs. intense pulsed light. Br J Dermatol. 2010;163:1007-13.

18. Fodor L, Carmi N, Fodor A, Ramon Y, Ullmann Y: Intense pulsed light for skin rejuvenation, hair removal, and vascular lesions: a patient satisfaction study and review of the literature. Ann Plast Surg 2009;62:345-9. 